\title{
Carboxy-methyl-cellulose hydrogel-filled breast implants - an ideal alternative? A report of five years' experience with this device
}

\author{
Christina A Brunner MD, Reinhard W Gröner MD
}

CA Brunner, RW Gröner. Carboxy-methyl-cellulose hydrogelfilled breast implants - an ideal alternative? A report of five years' experience with this device. Can J Plast Surg 2006;14(3):151-154.

The controversy over the potential health risks from exposure to silicone gel from breast implants has led to extensive research to improve the safety of silicone gel-filled implants. In addition, there has been simultaneous research directed toward the development of alternative filling materials, with the goal of a breast implant that would minimize health risks and maximize cosmetic attributes. In the present study, experience with a filler material that has textural characteristics similar to that of silicone gel, but which is biodegradable and can therefore be eliminated by the body in case of implant failure, is reported.

Since February 2000, the authors have been monitoring carboxymethyl-cellulose $(\mathrm{CMC})$ hydrogel breast implants as participants in a prospective clinical trial. CMC hydrogel is a biodegradable, nontoxic, nonmutagenic and viscoelastic gel, which has been in clinical use since 1984 and has been available as the Monobloc breast implant since 1994. For the present study, 122 patients who underwent surgery between February 2000 and February 2005 were evaluated. It was determined that CMC hydrogel implants have a higher radiotranslucency than silicone gel, and the integrity of this device was easy to prove by clinical examination. In case of rupture, the implant can be replaced immediately; it is easily inserted and can be placed through a small incision because of its highly elastic shell. The complication rate was very low, and the patients were highly satisfied. In terms of safety, the implant is comparable with saline, and its consistency is comparable with that of silicone gel.

Key Words: Biodegradable; CMC hydrogel; Nontoxic; In consistency comparable to with silicone gel
Implants mammaires remplis d'hydrogel à base de carboxyméthylcellulose : la solution de rechange idéale? Rapport d'expérience sur l'utilisation de la prothèse sur une période de cinq ans

La controverse autour des risques pour la santé liés à l'exposition au gel de silicone provenant d'implants mammaires a débouché sur une vaste recherche visant à améliorer l'innocuité des prothèses remplies au gel de silicone. Pendant ce temps, il s'est fait de la recherche sur la mise au point de nouvelles substances de remplissage qui permettraient à la fois de réduire au minimum les risques pour la santé et d'augmenter au maximum les attributs esthétiques. Le présent article fait état d'une étude expérimentale sur un produit de remplissage qui possède une texture comparable à celle du gel de silicone mais qui est biodégradable et qui, par conséquent, peut être éliminé de l'organisme en cas de fuite de l'implant. Depuis février 2000, les auteurs de l'article suivent l'évolution de prothèses mammaires remplies d'hydrogel à base de carboxyméthylcellulose (CMC), en tant que participants à un essai clinique prospectif. L'hydrogel de $\mathrm{CMC}$ est à la fois biodégradable, non toxique, non mutagène et viscoélastique; il est utilisé à différentes fins en pratique clinique depuis 1984, et son emploi dans les prothèses mammaires Monobloc remonte à 1994. Cent vingt-deux patientes opérées entre février 2000 et février 2005 ont été suivies dans le cadre de la présente étude. Il a été établi que l'hydrogel à base de $\mathrm{CMC}$ a une plus grande radiotransparence que le gel de silicone, et l'intégrité physique des prothèses est facile à vérifier par l'examen clinique. En cas de rupture, on peut remplacer l'implant aussitôt; comme son enveloppe est extrêmement souple, on peut le glisser facilement sous la peau et le placer dans la poitrine par une petite incision. Nous avons relevé un taux de complications très faible, et les patientes se montrent très satisfaites du résultat. L'hydrogel à base de $\mathrm{CMC}$ offre une innocuité comparable à celle de la solution saline et présente une texture comparable à celle du gel de silicone.
$\mathrm{T}$ The goal of many plastic surgeons is to find a breast implant that would minimize health risks associated with the filling material, yet maximize the ideal cosmetic possibilities. After the controversy over the potential health risks from exposure to silicone gel-filled breast implants, extensive research has been carried out to improve silicone gels in a way that would reduce the risks of gel bleed and gel migration.

Form-stable or cohesive gel implants may reduce this risk, but may not entirely eliminate it. As well, the public is still concerned with the risks associated with silicone gel implants.
In contrast, saline-filled breast implants are associated with a higher rate of implant rupture and/or rippling, and do not have the same textural properties that make silicone breast implants popular.

Based on our previous experiences, we are now able to report our experience of a filler material with textural characteristics similar to that of silicone gel, but which is biodegradable and can therefore be eliminated by the body in case of implant failure.

Carboxy-methyl-cellulose (CMC) consists of a cellulose polysaccharide weighing approximately $10,000 \mathrm{Da}$. It is soluble 

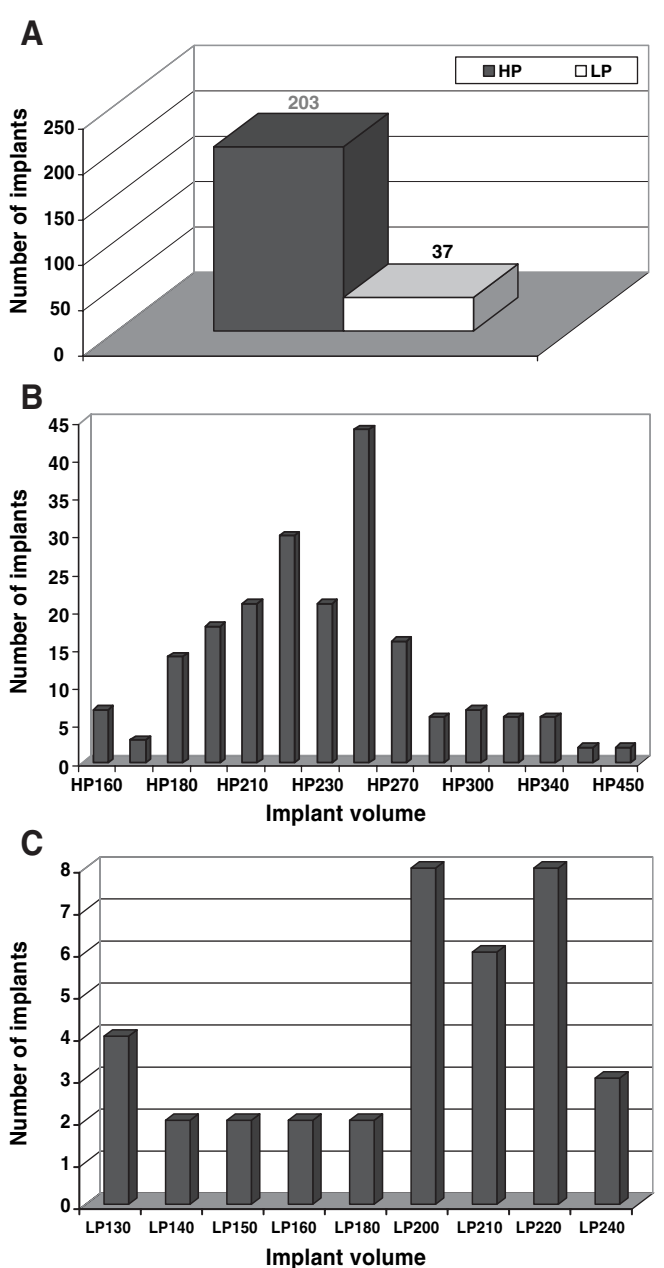

Figure 1) A Distribution of high-profile (HP) versus low-profile (LP) carboxymethyl cellulose hydrogel breast implants. B Distribution of different volumes of HP implants. C Distribution of different volumes (implant size) of LP implants

in water or serum, and remains stable at temperatures ranging from $10^{\circ} \mathrm{C}$ to $130^{\circ} \mathrm{C}$.

$\mathrm{CMC}$ is a natural product of photosynthesis that forms the skeleton of all plant life, and is therefore ubiquitous. It has served as the basis for many medications and materials implanted or instilled in the human body. It serves as a vehicle for medications, including eye lubricants (1) and plasma expanders (2,3), and as an intraperitoneal agent for adhesive prevention. CMC is also used in cellulose-based suture materials.

CMC hydrogel consists of 3.7\% CMC, 96.3\% saline and $6 \mathrm{ppm}$ methylene blue. It is a biodegradable, nontoxic, nonmutagenic, viscoelastic hydrogel, which has been tested in a variety of animal studies (4). As an implant-filling material, it has been in clinical use since 1984 (5), and available since 1994 as the Monobloc breast implant (Arion Laboratories, France). Both high-profile and low-profile implants are available to the surgeon.

\section{PATIENTS AND METHODS}

Since February 2000, the authors have used CMC hydrogel breast implants as participants in a prospective clinical study.

All patients were informed about the different filling materials of breast implants (silicone gel, saline and CMC hydrogel). They all signed a consent form, which indicated that they were to be participants in a prospective clinical study. Follow-up consultations were arranged after three, six and 12 months, respectively, followed by an annual consultation.

One hundred twenty-two patients, aged 19 to 54 years (mean age 30.9 years), who underwent surgery between February 2000 and February 2005, were included in the present report.

In total, $240 \mathrm{CMC}$ hydrogel breast implants were used in these patients: 82 patients $(67.2 \%)$ underwent surgery for primary breast augmentation, 20 patients $(16.4 \%)$ were treated for implant exchange (silicone gel to CMC hydrogel), nine patients $(7.4 \%)$ were corrected for breast asymmetry, and nine others $(7.4 \%)$ received breast augmentation with mastopexy. In two patients (1.6\%), a CMC hydrogel breast implant was used for secondary breast reconstruction after mastectomy and tissue expansion. High profile implants were inserted more frequently than low profile implants (84.6\% versus 15.4\%, respectively) (Figures 1A to 1C).

In all patients, surgery was performed under general anesthesia. All patients received an antibiotic in a single intravenous dose perioperatively, and all patients stayed overnight. A $14 \mathrm{CH}$ suction drain was used as standard, and was removed after $24 \mathrm{~h}$ (in rare cases after $48 \mathrm{~h}$ ).

Either an inframammary or periareolar approach, maximum $4 \mathrm{~cm}$ in length, was used as the preferred incision. Initially, a subglandular placement of the implant was used, but for the last three years of the study a biplane (subpectoral/subglandular) positioning of the implant was used for better soft tissue coverage in the mostly slender patients. This method was chosen as the standard approach independent of the filling material of the implants. All patients were instructed to wear a sports bra for three weeks (day and night), and then for a further three months during the day only.

\section{RESULTS}

Sixty-three $(51.7 \%)$ of the study participants were seen for postoperative follow-up in 2005, 22 patients (18.0\%) came for follow-up in 2004, and 27 patients (22.1\%) were seen in 2003. Five patients $(4.1 \%)$ were lost to follow-up after their sixmonth postoperative visit. Another five patients $(4.1 \%)$ had moved out of the country and therefore were not available for further assessment.

\section{Infection rate}

No infections were observed.

\section{Implant rupture or defect}

No implant rupture or implant defect occurred in the authors' collective series. However, one patient presented with a ruptured CMC hydrogel breast implant from an augmentation she had three years ago by another surgeon. A swelling of her breast had started six weeks before she came for surgery. She showed no signs of infection and had a normal blood cell count. Intraoperatively, a large seroma and a thin capsule with no signs of inflammation were found. After suction of the seroma and irrigation of the wound with saline, a new CMC hydrogel breast implant was placed. At three weeks' postoperative follow-up, the expanded skin envelope had completely contracted back to its normal size.

\section{Bleeding or seroma}

Unilateral hematomas occurred in two patients $(0.8 \%)$. One patient required a revision on the first postoperative day. A 

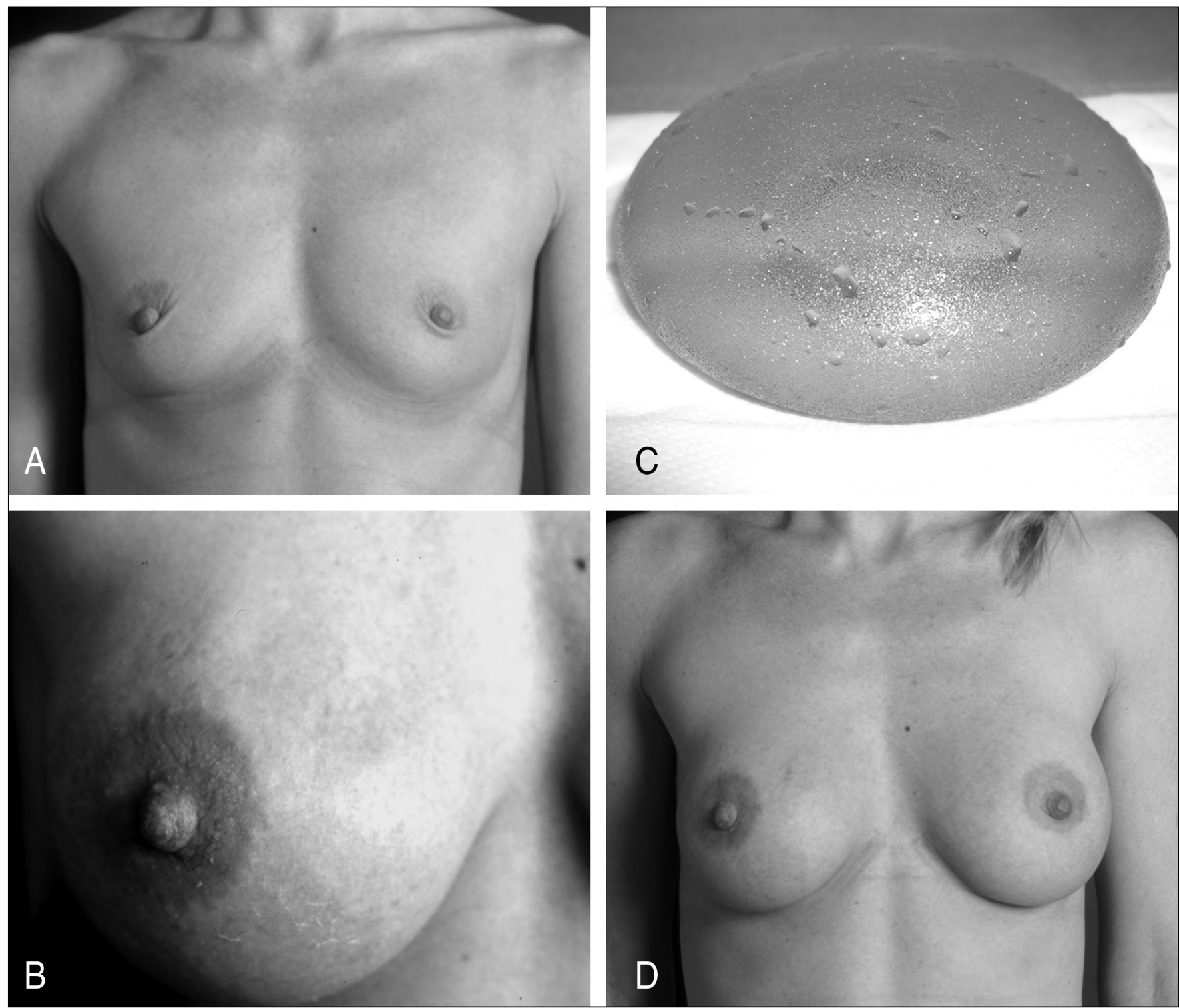

Figure 2) A Preoperative photograph of patient, who had one child at the time of surgery. The implant was inserted via a submammary approach and positioned epipectorally. B Wrinkling after birth of second child. C Carboxy-methyl-cellulose hydrogel implant intraoperatively, before reinsertion. $\mathrm{D}$ Patient one year following revision, with the implant in the subpectoral (biplane) position

second patient, within whom a dissolved silicon implant shell was found intraoperatively, was in the study as a candidate for implant change (silicone versus hydrogel). This required full capsulectomy, after which she experienced a swollen breast and a hematoma necessitating minor revision. A third patient, with a tubular breast deformity and breast asymmetry, suffered from a seroma and wound healing problems.

\section{Capsule contracture according to Baker classification III/IV}

Two patients $(0.8 \%$ of 240 hydrogel implants) suffered from unilateral capsule contracture. The patient who had developed a seroma at the time of her initial surgery suffered later from capsule contracture, which occurred shortly after birth of her child. She became pregnant four weeks after her surgery.

The second patient had surgery because of capsule contracture after a ruptured silicone gel-filled breast implant and extensive epi- and subpectoral siliconomas. The siliconomas were removed and the implant changed, but unfortunately the capsular contracture recurred less then one year after surgery. She was then treated by open capsulotomy and for three years there has been no recurrence.

\section{Wrinkling}

In two of the 122 patients (1.6\%), wrinkling on both breasts occurred. Both patients had had subglandular implants, and both became pregnant after primary surgery. One of the patients gained and lost more than $30 \mathrm{~kg}$ during the pregnancy. Both were treated by changing the implant position from subglandular to subpectoral, and achieved very satisfactory results (Figures $2 \mathrm{~A}$ to $2 \mathrm{D}$ ).

\section{Patient satisfaction}

One hundred three $(92 \%)$ patients reported their results as very good or good (Table 1$)$. Only one patient $(0.9 \%)$ was 


\section{TABLE 1}

Patient satisfaction with postoperative results

\begin{tabular}{lcc}
\hline Rating & $\mathbf{n}$ & $\%$ \\
\hline Very good & 88 & 78.6 \\
Good & 15 & 13.4 \\
Moderate & 8 & 7.1 \\
Displeased & 1 & 0.9 \\
Total $^{*}$ & 112 & 100 \\
\hline
\end{tabular}

${ }^{*} T e n$ of the original 122 patients were lost to follow-up. Of note, eight (7.1\%) patients reported pregnancies in the short-term postoperative follow-up

displeased with the operative result, which was independent of the implant.

\section{DISCUSSION}

In the past, variable results have been achieved in published reports of alternative filling materials, such as soybean oil $(6,7)$. This may have led to many surgeons being hesitant to use breast implants filled with substances other than silicone gel or saline.

After reviewing more than five years of experience with the CMC hydrogel-filled breast implant, there appears to be a negligable complication rate and a high rate of satisfaction in our patients. Similar results were observed previously (8).

Apart from wrinkling in very rare cases (which was not thought to be due to the filling material of the implant in our study), we did not find any medical disadvantages. In a previous study (9), wrinkling was described in rare cases after subglandular placement of the implant. Even if this does occur, it is comparatively easy to treat by repositioning of the implant or implant exchange (9). The CMC hydrogel implant is very easy to place due to its highly elastic shell, making it possible to insert it even using small incisions. This was very convincing, especially in comparison with cohesive silicone devices.

In addition, a big advantage of this implant is that its integrity can be easily proven by clinical examination. According to its chemical properties, the gel will bind with water as soon as there is a loss of integrity of the shell. This will

\section{REFERENCES}

1. Allarakhia L, Puumula M, Lindstrom RL. A test for crystalline lens biocompatibility. Eye 1991;5:113-9.

2. Buglov ED, Miklavskaia GM. [Determination of carboxymethylcellulose in biological fluids]. Lab Delo 1969;2:105-7.

3. Kamath KR, Park K. Biodegradable hydrogels in drug delivery. Adv Drug Deliv Rev 1993;11:59-84.

4. Bachmann E, Weber E, Post M, Zbinden G. Biochemical effects of gum arabic, gum tragacanth, methylcellulose and carboxymethylcellulose-Na in rat heart and liver. Pharmacology 1978;17:39-49.

5. Arion H. Carboxy-methyl cellulose hydrogels used to fill breast implants: 15 years of experience. Eur J Plast Surg 2001;24:172-5. lead to a swelling of the breast, which is easy to diagnose clinically, even by the patient herself.

In the case of rupture, there is virtually no health risk for the patient, due to the filling material of the implant being biocompatible and biodegradable. A ruptured implant can be replaced immediately and, thus, there is no need for a staged procedure for the patient.

In addition, there is no risk of silicone bleed or granuloma formation when using this type of device.

Compared with silicone gel breast implants, CMC hydrogel breast implants have a higher radiotranslucency, which plays a positive role in conventional mammography, although there may be no specific advantage in digital mammography.

A further advantage of the CMC hydrogel-filled implant is the natural feel, which is comparable with that of silicone gelfilled breast implants. These points were affirmed by patients after changing silicone gel-filled implants to CMC hydrogelfilled breast implants; in addition, some subjects found that the previously experienced 'cold breast' sensation resolved with the switch to CMC hydrogel-filled implants.

In conclusion, regarding our experience, we recommend the CMC hydrogel-filled breast implant as a good and safe alternative to silicone gel- or saline-filled implants, depending on the preferences of the patient.

\section{SUMMARY}

A prospective study was planned using CMC hydrogel as an alternative filling material to silicone gel and saline in breast implants. One hundred twenty-two patients who underwent surgery between February 2000 and February 2005 were included in the present report

Patient satisfaction with the CMC hydrogel implant was very high. The complication rate was very low (no implant failure, and capsule contracture rate was only $0.8 \%$ ). The main advantage of this implant is that it has all the safety features of a saline-filled implant with the textural feel of silicone. In addition, implant rupture can be easily clinically diagnosed and the implant can be changed immediately. A further advantage is the higher translucency for radiation, which facilitates mammography, in contrast to silicone gel-filled breast implants. From our experience, this product is the ideal alternative.

6. Kirkpatrick WN, Jones BM.The history of Trilucent implants, and a chemical analysis of the triglyceride filler in 51 consecutively removed Trilucent breast prostheses. Br J Plast Surg 2002;55:479-89.

7. Scuderi N, Mazzocchi M, Alfano C, Onesti MG. Prospective study on Trilucent soybean oil-filled breast prosthesis. Plast Reconstr Surg 2005;116:1130-6.

8. Valeriani M, Mezzana P, Madonna Terracina FS. Carboxy-methylcellulose hydrogel mammary implants: Our experience. Acta Chir Plast 2002;44:71-6.

9. Gatti A. Critical review of additive mastoplastic with Arion hydrogel prosthesis. Aesthetic Plast Surg 2004;28:54-6. 